ARTICLE

\title{
Light-driven formation of manganese oxide by today's photosystem II supports evolutionarily ancient manganese-oxidizing photosynthesis
}

Petko Chernev ${ }^{1,3}$, Sophie Fischer1, Jutta Hoffmann¹, Nicholas Oliver ${ }^{1}$, Ricardo Assunção ${ }^{1}$, Boram Yu1, Robert L. Burnap (D) 2, Ivelina Zaharieva (1) ${ }^{1}$, Dennis J. Nürnberg (D) ${ }^{1}$, Michael Haumann ${ }^{1}$ \& Holger Dau (D) ${ }^{1 凶}$

Water oxidation and concomitant dioxygen formation by the manganese-calcium cluster of oxygenic photosynthesis has shaped the biosphere, atmosphere, and geosphere. It has been hypothesized that at an early stage of evolution, before photosynthetic water oxidation became prominent, light-driven formation of manganese oxides from dissolved $\mathrm{Mn}(2+)$ ions may have played a key role in bioenergetics and possibly facilitated early geological manganese deposits. Here we report the biochemical evidence for the ability of photosystems to form extended manganese oxide particles. The photochemical redox processes in spinach photosystem-II particles devoid of the manganese-calcium cluster are tracked by visible-light and X-ray spectroscopy. Oxidation of dissolved manganese ions results in high-valent $\mathrm{Mn}(\mathrm{III}$, IV)-oxide nanoparticles of the birnessite type bound to photosystem II, with 50-100 manganese ions per photosystem. Having shown that even today's photosystem II can form birnessite-type oxide particles efficiently, we propose an evolutionary scenario, which involves manganese-oxide production by ancestral photosystems, later followed by downsizing of protein-bound manganese-oxide nanoparticles to finally yield today's catalyst of photosynthetic water oxidation.

\footnotetext{
${ }^{1}$ Physics Department, Freie Universität Berlin, Arnimallee 14, 14195 Berlin, Germany. ${ }^{2}$ Department of Microbiology and Molecular Genetics, Oklahoma State University, Stillwater, OK 74078-4034, USA. ${ }^{3}$ Present address: Department of Chemistry - Ångström Laboratory, Molecular Biomimetics, Uppsala University, Lägerhyddsvägen 1, 75120 Uppsala, Sweden. ${ }^{凶}$ email: holger.dau@fu-berlin.de
} 
$\mathrm{N}$ ature's invention of photosynthetic water oxidation about three billion years ago (or even earlier ${ }^{1}$ ) was a breakpoint in Earth's history because it changed the previously anoxic atmosphere to today's composition with $\sim 21 \% \mathrm{O}_{2}$, practically depleting the oceans of ferrous iron and divalent manganese due to metal-oxide precipitation ${ }^{2,3}$. Water oxidation is catalyzed by a unique bioinorganic cofactor, denoted $\mathrm{Mn}_{4} \mathrm{CaO}_{5}$ according to its oxo-bridged metal core, which is bound to amino acids of the proteins of photosystem II (PSII) in the thylakoid membrane (Fig. 1) ${ }^{4-8}$. This catalyst originally developed in (prokaryotic) cyanobacteria, which were later incorporated by endosymbiosis into the ancestor of the (eukaryotic) cells of algae and plants to yield the chloroplast organelles9. The central PSII proteins as well as $\mathrm{Mn}_{4} \mathrm{CaO}_{5}$ (and its main catalytic performance features) are strictly conserved among photosynthetic organisms ${ }^{10,11}$.

Native PSII operates as a light-driven oxidoreductase (Fig. 1). Upon sequential excitation with four visible-light photons, four electrons from two bound water molecules are transferred from $\mathrm{Mn}_{4} \mathrm{CaO}_{5}$ to a redox-active tyrosine $\left(\mathrm{Y}_{\mathrm{Z}}\right)$ at the donor side and then via a cofactor chain to terminal quinone acceptors at the stromal side so that two reduced quinols as well as $\mathrm{O}_{2}$ and four protons are released during each catalytic water oxidation cycle $^{5,7,12-14}$. Starting from a $\mathrm{Mn}(\mathrm{III})_{3} \mathrm{Mn}(\mathrm{IV}) \mathrm{Y}_{\mathrm{Z}}$ state, the catalytic cycle involves alternate electron and proton abstraction to reach a $\mathrm{Mn}(\mathrm{IV})_{4} \mathrm{Y}_{\mathrm{Z}}$ ox state followed by (concomitant) Mn rereduction, $\mathrm{O}-\mathrm{O}$ bond formation and $\mathrm{O}_{2}$ release (Fig. 1) ${ }^{15}$. The exceptionally efficient $\mathrm{Mn}_{4} \mathrm{CaO}_{5}$ catalyst has inspired development of synthetic water-oxidizing materials ${ }^{16-18}$. Among the wealth of findings on water oxidation by Mn-based catalysts, here the following two results are of particular importance: (i) Selfassembly of the $\mathrm{Mn}(\mathrm{III} / \mathrm{IV})_{4} \mathrm{CaO}_{5}$ core in PSII is a light-driven process, involving step-wise oxidation of four solvent $\mathrm{Mn}^{2+}$ ions by $\mathrm{Y}_{\mathrm{Z}}{ }^{\text {ox }}$ coupled to electron transfer to the quinones ${ }^{19,20}$. (ii) Many amorphous Mn oxides of the birnessite type show significant water oxidation activity and share structural as well as functional features with the $\mathrm{Mn}_{4} \mathrm{CaO}_{5}$ core of the biological catalyst $^{21-25}$.

The evolutionary route towards the present water oxidation catalyst in PSII is much debated ${ }^{2,26-31}$. It has been hypothesized that before the evolution of oxygenic photosynthesis an ancestral photosystem developed the capability for light-driven oxidation of dissolved $\mathrm{Mn}^{2+}$ ions towards the $\mathrm{Mn}(\mathrm{III} / \mathrm{IV})$ level, thereby providing the reducing equivalents (electrons) needed for primary biomass formation by $\mathrm{CO}_{2}$ fixation ${ }^{32,33}$. Aside from the implications for biological evolution, photosynthetic Mn-oxide formation has significance in the context of recent hypotheses to account for geologic $\mathrm{Mn}$ deposits, for example from the early Paleoproterozoic in South Africa ${ }^{2,33}$. Notably, the process of continuous $\mathrm{Mn}^{2+}$ oxidation is chemically not trivial, because suitable redox potentials alone are insufficient. Because solitary $\mathrm{Mn}(\mathrm{III} / \mathrm{IV})$ ions are not stable in aqueous solution, the ability of the photosystem to stabilize high-valent $\mathrm{Mn}$ ions by the efficient formation of extended Mn (oxide) structures is pivotal.

Here, the experimental evidence is provided that today's PSII, depleted of its native $\mathrm{Mn}_{4} \mathrm{CaO}_{5}$ complex and the membraneextrinsic polypeptides, can form a Mn(III/IV) oxide of the birnessite type. By optical (UV-visible) and X-ray absorption spectroscopy, we show that the light-driven oxidation of $\mathrm{Mn}^{2+}$ ions results in Mn-oxide nanoparticles which are bound to the photosystem, thereby supporting that also ancient photosystems could have produced Mn oxides and suggesting a viable evolutionary route to today's catalyst of photosynthetic water oxidation.

\section{Results}

Spinach photosystems depleted of $\mathrm{Mn}_{4} \mathrm{CaO}_{5}$ and extrinsic polypeptides. Figure 1 shows the arrangement of protein subunits and cofactors in PSII. A recent crystallographic study has revealed that the metal-binding amino acids are similarly arranged in PSII with or without $\mathrm{Mn}_{4} \mathrm{CaO}_{5}$, with the voids in the Mndepleted photosystem being filled by water molecules ${ }^{34}$. Only in the absence of the Mn-stabilizing extrinsic proteins, sufficient room for the incorporation of a Mn-oxide nanoparticle into the PSII structure may exist (Fig. 1). Therefore, we explored the ability of purified PSII, depleted of $\mathrm{Mn}_{4} \mathrm{CaO}_{5}$ and the extrinsic proteins, to form Mn-oxide species in vitro. PSII-enriched membrane particles were prepared from spinach $^{35}$ and $\mathrm{Mn}$ depletion was achieved using an established protocol (see Supplementary Information) ${ }^{36}$. The resulting PSII preparation was inactive in light-driven $\mathrm{O}_{2}$-evolution and $\mathrm{Mn}$ was practically undetectable, i.e., $<0.2 \mathrm{Mn}$ ions per PSII were found (Table 1). Concomitantly with $\mathrm{Mn}$ depletion, the three proteins bound to
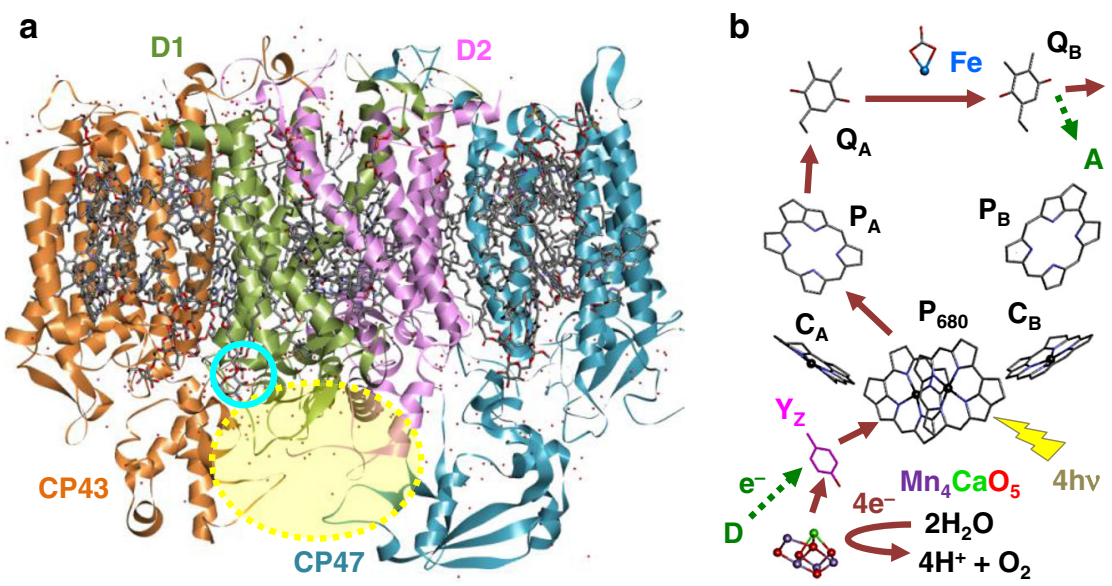

Fig. 1 Structure and function of photosystem II. a Cryo-electron microscopy structure of native plant PSII (PDB entry $5 X N L$ ). The central membraneintegral subunits with cofactors of a PSII monomer are shown (cyan circle $=\mathrm{Mn}_{4} \mathrm{CaO}_{5}$ position). Omitting the extrinsic subunits (PsbQ, PsbP, and PsbO with approximate molecular weights of 18, 24, and $33 \mathrm{kDa}$ ) exposes a cavity (yellow shading, the subunits are absent in our Mn-depleted PSII). $\mathbf{b}$ Cofactors (truncated structures) for light-driven electron transfer in $\mathrm{D} 1 / \mathrm{D} 2$ ( $\mathrm{Y}_{\mathrm{Z}}$, tyrosine electron acceptor from $\mathrm{Mn}_{4} \mathrm{CaO}_{5} ; \mathrm{P}_{680}$, primary donor chlorophyll (chl) dimer; $C_{A, B}$, accessory chl; $P_{A . B}$, pheophytins; $Q_{A, B}$, acceptor quinones; Fe, non-heme iron with bicarbonate ligand). Green/dark-red arrows: electron transfer paths upon photo-excitation $(h \nu)$ of $\mathrm{O}_{2}$-evolving or $\mathrm{Mn}$-depleted PSII (D/A, external electron donor/acceptor). 
Table 1 Metal content of PSII preparations (for details, see Supplementary Table 1).

\section{Preparation}

Intact $\left(\mathrm{O}_{2}\right.$ evolving) PSII

Mn-depleted (non- $\mathrm{O}_{2}$ evolving) PSII

Mn-depleted PSII + $250 \mu \mathrm{M} \mathrm{MnCl}_{2}$, dark

Mn-depleted PSII + $250 \mu \mathrm{M} \mathrm{MnCl}_{2}$, light
Mn per PSII

$4 \pm 1$

$<0.2 \pm 0.2$

$7 \pm 2$

$65 \pm 19$<smiles>O=C(O)c1ccc(Nc2cc(Cl)c(O)c(Cl)c2)cc1</smiles>

Fig. 2 Redox reaction associated with a color change of DCPIP (2,6dichlorophenol-indophenol). The color of the oxidized molecule (DCPIPox, left) is blue; the reduced molecule (DCPIPred, right) is colorless.

the lumenal side of plant PSII (the so-called extrinsic proteins PsbQ, PsbP, and PsbO) $)^{37,38}$ were removed, as revealed by polarography, total reflection X-ray fluorescence (TXRF) ${ }^{39}$ metal quantification, and gel electrophoresis (Supplementary Figs. 1 and 2; Table 1, Supplementary Table 1).

UV-vis spectra monitor PSII electron transfer. Optical absorption spectroscopy was employed for time-resolved tracking of PSII redox chemistry (Figs. 2-4 and Supplementary Figs. 3-8 and 10,11). DCPIP (2,6-dichlorophenol-indophenol) was added as an artificial electron acceptor for PSII that allows facile optical monitoring of light-driven electron flow ${ }^{40}$. Oxidized DCPIP (DCPIP ${ }^{\circ}$ ) at $\mathrm{pH} \geq 7$ shows strong absorption at $604 \mathrm{~nm}$ and its bright blue color vanishes upon reduction (Figs. 2 and 3, see also Supplementary Fig. 4$)^{41}$. We explored the ability of DCPIPox to support and simultaneously probe PSII electron transfer by recording absorption spectra as a function of illumination period, light intensity and DCPIP concentration using intact (not Mndepleted) PSII membrane particles (Supplementary Figs. 3-5). Mn-depleted PSII showed a completely different electron transfer behavior (Figs. 3, 4 and Supplementary Figs. 6-8 and 11). By adding a $\mathrm{Mn}$ salt $\left(\mathrm{MnCl}_{2}\right)$, we investigated hexaquo- $\mathrm{Mn}^{2+}$ ions as an exogenous electron donor to PSII. $\mathrm{Mn}^{2+}$ in solution is completely colorless, i.e., it does not absorb in the 300-900 $\mathrm{nm}$ region. In the dark in the presence of DCPIPox and $\mathrm{Mn}^{2+}$ ions or upon illumination in the absence of $\mathrm{Mn}^{2+}$, we did not observe any major spectral change of the PSII suspension (aside from minor bleaching of PSII chlorophyll due to oxidative damage ${ }^{42}$ ). No absorption changes accountable to DCPIP (i.e., due to its reduction) under illumination were observed in the presence of $\mathrm{MnCl}_{2}$ with simultaneous absence of PSII (Supplementary Fig. 10). These experiments verify for the Mn-depleted PSII: electron transfer towards DCPIP requires both, visible light to drive the PSII electron transfer reactions and $\mathrm{Mn}^{2+}$ ions that can serve as a donor in the light-induced electron transfer.

Electron donation by $\mathrm{Mn}^{2+}$ ions. At low $\mathrm{MnCl}_{2}$ concentration $(5 \mu \mathrm{M})$, a linear decrease in the amount of DCPIPox indicates a small and constant rate of electron donation at the PSII donor side (Figs. 3, 4), which is only about $8 \%$ of the level reached in intact PSII due to water oxidation (see Supplementary Figs. 7-9 for further data and discussion). This slow electron transfer is not visible at higher $\mathrm{MnCl}_{2}$ concentrations suggesting that at high $\mathrm{MnCl}_{2}$ concentrations, the PSII centers do not maintain a metal a
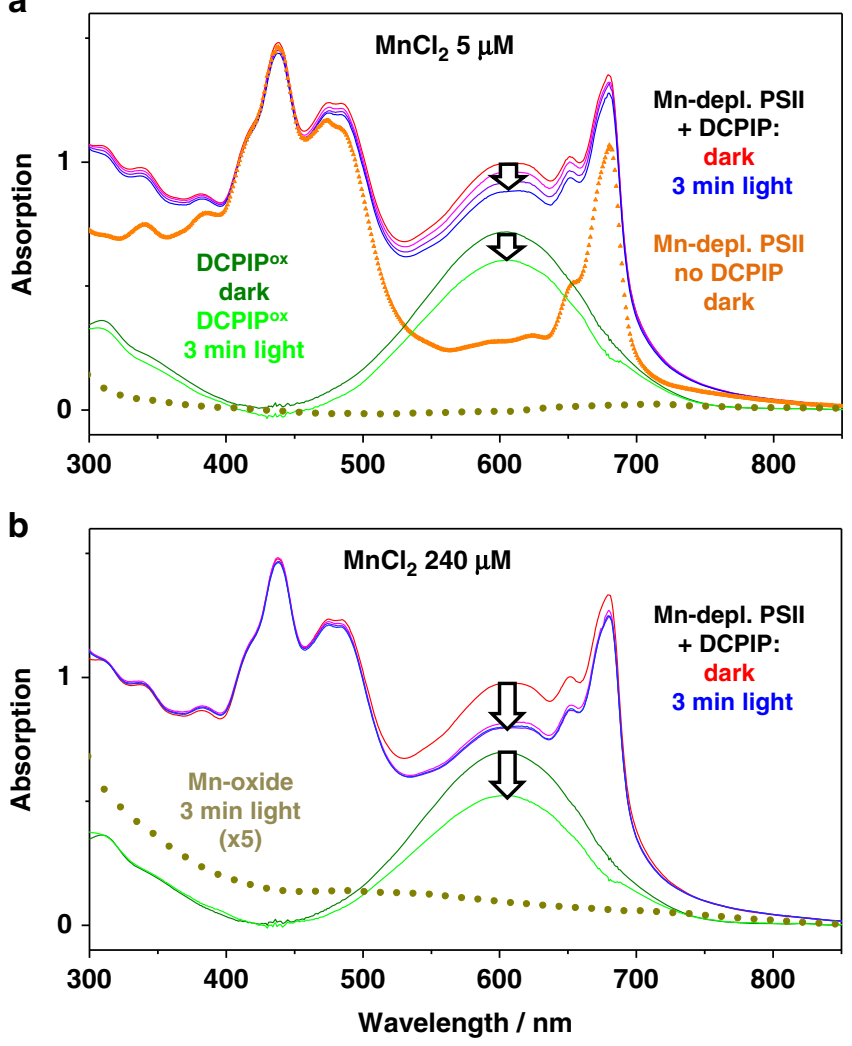

Fig. 3 Light-driven redox reactions in Mn-depleted PSII tracked by optical spectroscopy. a, b UV-vis absorption spectra. The orange line (triangles) represents a suspension of Mn-depleted PSII before the addition of DCPIP $(60 \mu \mathrm{M})$ serving as artificial electron acceptor (buffer conditions: $1 \mathrm{M}$ glycine-betaine, $15 \mathrm{mM} \mathrm{NaCl}, 5 \mathrm{mM} \mathrm{CaCl}, 5 \mathrm{mM} \mathrm{MgCl}$, $25 \mathrm{mM} \mathrm{MES}$ buffer, $\mathrm{pH} 7$; for further details see $\mathrm{SI}$ ). Then DCPIPox and either $5 \mu \mathrm{M}$ $\mathrm{MnCl}_{2}$ (in a) or $240 \mu \mathrm{M} \mathrm{MnCl}_{2}$ (in b) were added, followed by continuous white-light illumination $\left(1000 \mu \mathrm{E} \mathrm{m}^{-2} \mathrm{~s}^{-1}\right)$ of the PSII suspensions and collection of spectra (one spectrum per minute; immediately prior to illumination, red lines, and after 3 min light, blue lines). The green and lightgreen lines correspond to the spectral contributions of DCPIPox to the dark and 3-min light spectra; the amplitude decrease at $604 \mathrm{~nm}$ represents the loss of DCPIPox due to its reduction by PSII (arrows). The dark-yellow dotted spectra are assignable to a Mn oxide, as verified by $\mathrm{X}$-ray absorption spectroscopy (spectra obtained by weighted spectral deconvolution, see caption of Supplementary Fig. 6, and scaled by a factor of 5, for clarity). Note that significant spectral changes due to $\mathrm{Mn}$-oxide formation were only observed with $240 \mu \mathrm{M} \mathrm{MnCl}_{2}$ (in b), but not with $5 \mu \mathrm{M} \mathrm{MnCl}_{2}$ (in a).

Source data are provided as a Source Data file.

site that supports continuous low-rate electron transfer. Therefore we consider this phenomenon, albeit of clear interest for future investigation, irrelevant for the analysis of oxide formation herein observed at higher $\mathrm{MnCl}_{2}$ concentrations. For increasing $\mathrm{MnCl}_{2}$ concentrations, a clearly more rapid phase of DCPIP ${ }^{\text {ox }}$ reduction grew in (Fig. 3, arrows; Fig. 4 and Supplementary Fig. 8). Its amplitude saturated at $240 \mu \mathrm{M} \mathrm{MnCl}$ and indicates reduction of $\sim 17 \%(\sim 10 \mu \mathrm{M})$ of the initial DCPIPox $(60 \mu \mathrm{M})$, which corresponds to up to 200 transferred electrons per PSII within about 1 min. Notably, at low $\mathrm{MnCl}_{2}$ concentration DCPIP reduction continued at undiminished rate for a clearly longer illumination time ( $>5$ min, Fig. 4 and Supplementary Fig. 7 ), suggesting that photoinhibitory damage does not rapidly terminate electron transfer in the Mn-depleted PSII. Based on the Mn concentration dependence (Fig. 4 and Supplementary Fig. 8) and the results presented in the following, we can assign this rapid DCPIP 


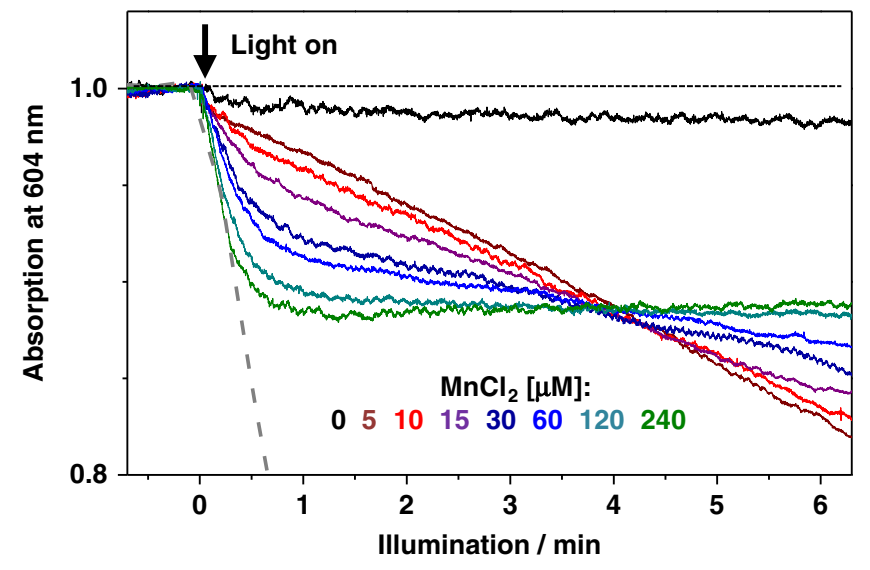

Fig. 4 Kinetics of light-dependent electron flow in Mn-depleted PSII at various concentrations of solvated $\mathbf{M n}^{\mathbf{2}+}$ ions. The decrease in absorption at $604 \mathrm{~nm}$ monitors the light-driven reduction of the artificial electron acceptor ( $60 \mu \mathrm{M}$ DCPIPox, $\mathrm{pH} 7$ ) due to the oxidation of $\mathrm{Mn}^{2+}$ ions by PSII. See Supplementary Fig. 7 for traces on a longer time scale. The gray dashed line illustrates the rate of DCPIP reduction by fully intact PSII under similar conditions (Supplementary Fig. 5). Source data are provided as a Source Data file.

reduction phase to oxidation of $\mathrm{Mn}^{2+}$ ions and formation of high-valent $\mathrm{Mn}(\mathrm{III} / \mathrm{IV})$ oxide particles. At $240 \mu \mathrm{M} \mathrm{MnCl}_{2}$, DCPIP reduction is completed after about $1 \mathrm{~min}$ of illumination likely indicating that further electron donation to the PSII donor side (and thus further DCPIP reduction) was impaired after the formation of a Mn-oxide particle at the PSII donor side, possibly by blocking access of further $\mathrm{Mn}^{2+}$ ions to the oxidant, which is the tyrosine $\left(\mathrm{Y}_{\mathrm{Z}}\right)$ radical (see Fig. 1).

UV-vis spectra point towards Mn-oxide formation. To search for evidence of Mn-oxide formation, informative absorption difference spectra of Mn-depleted PSII before and after illumination were calculated (Fig. 3 and Supplementary Fig. 6). For 60 $\mu \mathrm{M} \mathrm{MnCl}$, after completion of rapid DCPIPox reduction (3 min), there was a broad absorption increase (ranging from 350 to 700 $\mathrm{nm}$ ), which is similar to the wide-range absorption of Mn oxi$\mathrm{des}^{25}$. For higher concentrations of $\mathrm{MnCl}_{2}$, the absorption assigned to $\mathrm{Mn}$ oxides gained strength and became maximal at $240 \mu \mathrm{M} \mathrm{MnCl} \mathrm{M}_{2}$ (Fig. 3). Using alternative electron acceptors (Supplementary Fig. 11), similar or even higher Mn-oxide amounts were detected with DCBQ (2,5-dichloro-1,4-benzoquinone) or PPBQ (phenyl-p-benzoquinone), resembling the native quinone acceptor $\left(\mathrm{Q}_{\mathrm{B}}\right)$, but the slow (hydrophilic) acceptor ferricyanide $\left(\mathrm{K}_{3} \mathrm{Fe}^{\mathrm{III}}(\mathrm{CN})_{6}\right)$ did not yield significant Mn-oxide formation.

PSII with 50-100 bound Mn ions prepared for analysis by $\mathrm{X}$ ray spectroscopy. To investigate the $\mathrm{Mn}^{2+}$ oxidation products and identify their atomic structure, we employed X-ray absorption spectroscopy (XAS) at the Mn K-edge (Fig. 5 and Supplementary Figs. 12-16). Mn-depleted PSII was illuminated for 3 min with $240 \mu \mathrm{M} \mathrm{MnCl}_{2}$ and $60 \mu \mathrm{M} \mathrm{PPBQ}{ }^{\text {ox }}$ at $\mathrm{pH} 8.5$ or $\mathrm{pH} 7$ (Fig. 5, Supplementary Figs. 14 and 15), the reaction was terminated by rapid sample cooling in the dark, and the PSII membranes were pelleted by centrifugation and then transferred to XAS sample holders, followed by freezing in liquid nitrogen and later collection of X-ray spectra at $20 \mathrm{~K}$ (see SI). The metal content was determined by X-ray fluorescence analytics (Table 1, Supplementary Table 1), revealing $65 \pm 19 \mathrm{Mn}$ ions per initially Mn-depleted PSII after illumination in the presence of $240 \mu \mathrm{M}$
$\mathrm{MnCl}_{2}$. The calcium content in the PSII-formed $\mathrm{Mn}$ oxide could not be reliably determined because $\mathrm{CaCl}_{2}$ was present in the buffer and $\mathrm{Ca}$ is known to bind nonspecifically to the used PSII membrane particle preparation (Supplementary Table 1$)^{43}$.

X-ray spectroscopy reveals extended Mn(III/IV) oxides. The shape of the XANES (X-ray absorption near-edge structure) pronouncedly differed from hexaquo- $\mathrm{Mn}^{2+}$, micro-crystalline Mn oxides $\left(\mathrm{Mn}_{2}{ }_{2} \mathrm{O}_{3}, \mathrm{Mn}^{\mathrm{II}, \mathrm{III}_{3}} \mathrm{O}_{4}, \beta-\mathrm{Mn}^{\mathrm{IV}} \mathrm{O}_{2}\right)$, and native PSII, but was similar to layered $\mathrm{Mn}(\mathrm{III}, \mathrm{IV})$ oxides denoted as birnessite $^{44-46}$ (Fig. 5a). The K-edge energy indicated a mean redox level of about +3.5 , suggesting equal amounts of $\mathrm{Mn}$ (III) and $\mathrm{Mn}$ (IV) ions (Fig. 5a, Supplementary Fig. 12). EXAFS (extended Xray absorption fine structure) analysis revealed the atomic structure of the PSII-bound Mn oxide (Fig. 5b, Supplementary Fig. 14; Supplementary Table 2). The EXAFS of Mn-depleted PSII with bound $\mathrm{Mn}$ oxide closely resembled birnessite in showing a similar main $\mathrm{Mn}-\mathrm{O}$ bond length $(\sim 1.90 \AA)$, minor longer $\mathrm{Mn}-\mathrm{O}$ bond length contributions ( $2.30 \AA$, assignable to Jahn-Teller elongated $\mathrm{Mn}-\mathrm{O}$ distances of $\mathrm{Mn}^{\mathrm{III}}$ ions) as well as similar main and minor Mn-Mn distances $(\sim 2.88 \AA, \sim 3.45 \AA)$. Also, longer Mn-Mn distances $(\sim 5.00 \AA, \sim 5.54 \AA)$ were similar. On the other hand, the EXAFS spectra differ clearly from $\mathrm{Mn}(\mathrm{III})_{2} \mathrm{O}_{3}$ and $\beta$ $\mathrm{Mn}(\mathrm{IV}) \mathrm{O}_{2}$. The metrical parameters from EXAFS simulations are in good agreement with earlier data for the here studied and related Mn-oxide species of the birnessite-type $21,22,25,47,48$. We note that the long-range order in the oxide particles produced by PSII even exceeds that of the herein used reference oxides of the birnessite-type, as indicated by the magnitudes of the Fourier peaks assignable to the 2.87 and $5.54 \AA$ distances, verifying formation of a comparably extended and well-ordered Mn oxide. Notably, according to the similar XAS spectra, a similar birnessite-type $\mathrm{Mn}$ (III,IV)-oxide was formed (i) in the presence as well as absence of $\mathrm{CaCl}_{2}$ in the illumination buffer and (ii) at pH-values of 8.5 as well as 7.0 (Fig. 5 and Supplementary Fig. 15). The number of 50-100 Mn ions per PSII suggests that the Mn oxides could be bound to PSII in form of small nanoparticles $(<2 \mathrm{~nm})$.

Mn-oxide nanoparticles are bound to the PSII core complex. In the experiments reported above, PSII membrane particles were investigated. These are comparably large membrane fragments containing numerous PSII units per fragment and therefore can be collected by centrifugation at comparably low speed $(20,000 \times$ $g$ for $10 \mathrm{~min}$ ). These centrifugation conditions do not allow for pelleting of unbound oxide nanoparticles of only about $100 \mathrm{Mn}$ ions (diameter $<2 \mathrm{~nm}$ ), suggesting that the Mn-oxide nanoparticles are bound to the PSII membrane particles. To exclude that the Mn-oxide nanoparticles were bound to the lipid bilayer membrane or trapped between stacked membrane sheets, we also investigated detergent solubilized, membrane-free PSII particles using the same protocol for light-induced Mn-oxide formation as used for the PSII membrane particles. Speciation by EXAFS spectroscopy (Supplementary Fig. 16) verified that the same Mn oxide is formed also for detergent-solubilized PSII, thereby providing support for association of Mn-oxide nanoparticles directly with the PSII proteins.

\section{Discussion}

Mn-oxide formation by PSII. We have obtained the first direct experimental evidence that PSII devoid of $\mathrm{Mn}_{4} \mathrm{CaO}_{5}$ is capable of forming $\mathrm{Mn}$ (III,IV)-oxide particles of the birnessite type by lightdriven oxidation of $\mathrm{Mn}^{2+}$ ions. Presumably these are nanoparticles of 50-100 Mn ions that are bound to the PSII protein complex, as suggested by their presence in PSII membrane 

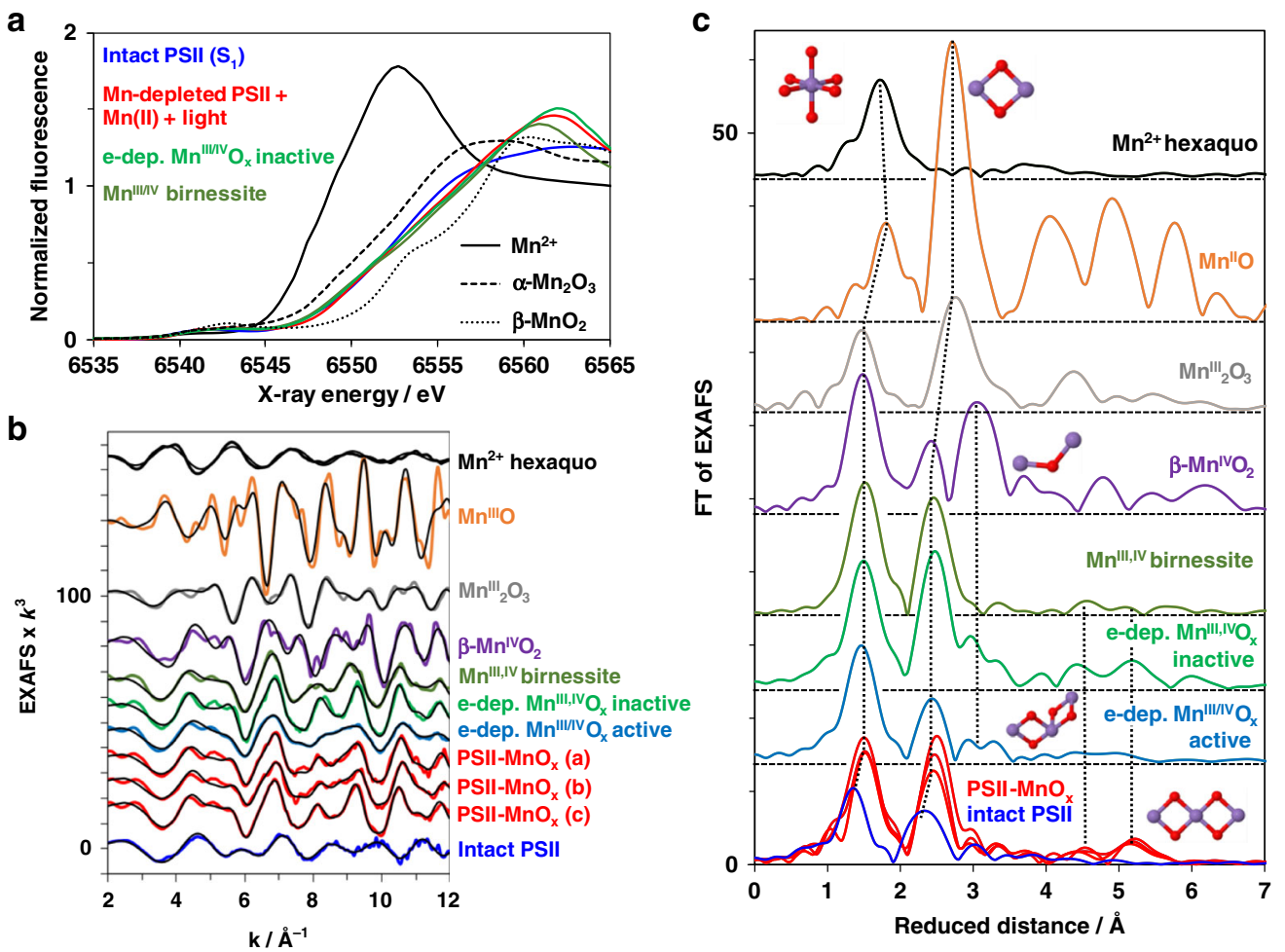

Fig. 5 X-ray absorption spectroscopy evidencing PSII-bound Mn oxide of the birnessite-type. a XANES spectra of the native PSII with its active-site Mn $(\mathrm{III})_{2} \mathrm{Mn}(\mathrm{IV})_{2} \mathrm{CaO}_{5}$ cluster (blue line) and $\mathrm{Mn}$-depleted PSII after the light-driven formation of $\mathrm{Mn}$ oxide (red lines) are compared to the spectra of $\mathrm{Mn}^{2+}$ in solution (solid black line), electrodeposited Mn oxide (green line), synthetic birnessite (dark green line) and further Mn oxides (dashed and dotted black lines). $\mathbf{b}$ The corresponding EXAFS spectra in $k$-space as in a as well as spectra of further Mn compounds. c Fourier-transformed (FT) EXAFS spectra (as in b) of: $\mathrm{Mn}^{2+}$ ions in solution, indicated reference $\mathrm{Mn}$ oxides, the $\mathrm{Mn}_{4} \mathrm{CaO}_{5}$ cluster in intact PSII, and Mn-depleted PSIl after illumination in the presence of $\mathrm{Mn}^{2+}$. Structural motifs corresponding to the individual peaks are schematically shown; FT peaks relating to the same structural motif are connected by dotted lines. Mn-depleted PSII particles $\left(20 \mu \mathrm{gL}^{-1}\right.$ chlorophyll) were illuminated for $3 \mathrm{~min}\left(1000 \mu \mathrm{E} \mathrm{m}^{-2} \mathrm{~s}^{-1}\right)$ in the presence of $240 \mu \mathrm{M} \mathrm{MnCl} \mathrm{M}_{2}$ and 60 $\mu \mathrm{M}$ PPBQ (buffer conditions: $1 \mathrm{M}$ glycine-betaine, $15 \mathrm{mM} \mathrm{NaCl}, 5 \mathrm{mM} \mathrm{CaCl}, 5 \mathrm{mM} \mathrm{MgCl}, 25 \mathrm{mM} \mathrm{MES} \mathrm{buffer,} \mathrm{pH} \mathrm{8.5;} \mathrm{similar} \mathrm{data} \mathrm{for} \mathrm{pH} 7.0$ is shown in Supplementary Fig. 15) and subsequently collected by centrifugation. (The spectrum shown in a as a red line represents the mean of the three spectra from individual samples shown in $\mathbf{b}$ and $\mathbf{c}$ as red lines as obtained after subtraction of a $5 \%$ aqueous $\mathrm{Mn}^{2+}$ contribution. See Supplementary Table 2 for details and further data.) Source data are provided as a Source Data file.

particle pellets, due to co-sedimentation using a comparably mild centrifugation protocol, as well as in solubilized, membrane-free PSII core particles after their precipitation. Is it possible that larger $\mathrm{Mn}$-oxide particles are formed (e.g., several thousand $\mathrm{Mn}$ ions), which would sediment also at moderate centrifugation speed? The cooperation of many PSII centers in formation of a single large Mn-oxide nanoparticle is unlikely, inter alia because efficient electron transfer from $\mathrm{Mn}^{2+}$ ions to the redox-active tyrosine cannot occur over distances that are as long as the distance between neighboring PSII dimers in PSII membrane particles and even more so for solubilized PSII. Similarly, also the fast spontaneous fusion of Mn-oxide nanoparticles to more extended oxide particles is highly unlikely. Aggregation mediated by nonbonding interactions cannot be rigorously excluded, but is disfavored by the expected concentrations of oxide particles in the sub-micromolar range. On these grounds and supported by the inhibitory effect of Mn-oxide formation on electron donation (Fig. 4 and Supplementary Fig. 8), we assume that Mn-oxide nanoparticles are bound to the PSII core complex, likely in the vicinity of the redox-active tyrosine $\left(\mathrm{Y}_{\mathrm{Z}}\right.$ in Fig. 1).

Light-driven $\mathrm{Mn}^{2+}$ oxidation also can promote self-assembly of the functional $\mathrm{Mn}_{4} \mathrm{CaO}_{5}$ complex, which is a comparably inefficient (low quantum yield) low-light process denoted as photoactivation 19,20 . Cheniae et al. investigated photoactivation and observed light-driven binding of about 18 membrane-bound $\mathrm{Mn}$ ions per PSII if $\mathrm{Ca}$ ions were excluded from the photoassembly buffer ${ }^{49}$, whereas we here observe binding of clearly more Mn ions ( $65 \pm 19 \mathrm{Mn}$ ions, Table 1), irrespective of the absence or presence of $\mathrm{Ca}$ ions at a moderate concentration $(5 \mathrm{mM})$ in the photoassembly buffer (Supplementary Fig. 14). The presence of $5 \mathrm{mM} \mathrm{CaCl}_{2}$ allows for photoactivation, although a higher concentration is required for optimal photoactivation yield ${ }^{49,50}$. The about 20 times higher light intensities we used likely promoted the oxidation and binding of numerous $\mathrm{Mn}$ ions at the expense of formation of a single native $\mathrm{Mn}_{4} \mathrm{CaO}_{5}$ cluster, because the latter requires low-light intensities presumably due to the presence of a slow 'dark rearrangement' step for assembly ${ }^{19}$.

Since Cheniae's work ${ }^{49}$, it had remained an open question in what form a larger number of $\mathrm{Mn}$ ions can bind to PSII membrane particles. Coordination of individual high-valent $\mathrm{Mn}$ ions to protein groups is one possibility (as often observed for divalent cations and trivalent $\mathrm{Fe}$ ions); the formation of extended protein-bound Mn-oxide nanoparticles is another possibility. Under our high-light conditions, Mn(III,IV)-oxide formation clearly is dominant. The Mn-oxide cluster size seems to be limited to around $100 \mathrm{Mn}$ ions, which may correspond to a nanoparticle of about $20 \AA$ in diameter (Fig. 6a). Such a particle may well be formed within the PSII cavity that becomes solvent-exposed upon removal of the extrinsic protein subunits (Fig. 1). These subunits are evolutionarily younger than the PSII core proteins ${ }^{51}$ and are absent in related anoxygenic photosystems ${ }^{52}$. Thus, it is well conceivable that an early PSII ancestor would have lacked these 
a

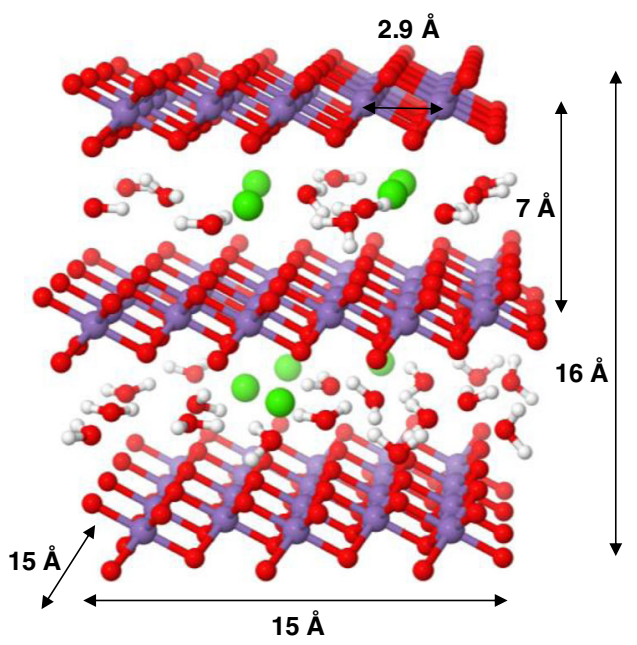

b

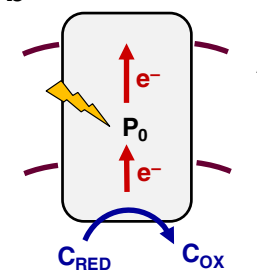

1

Anoxygenic Photosynthesis
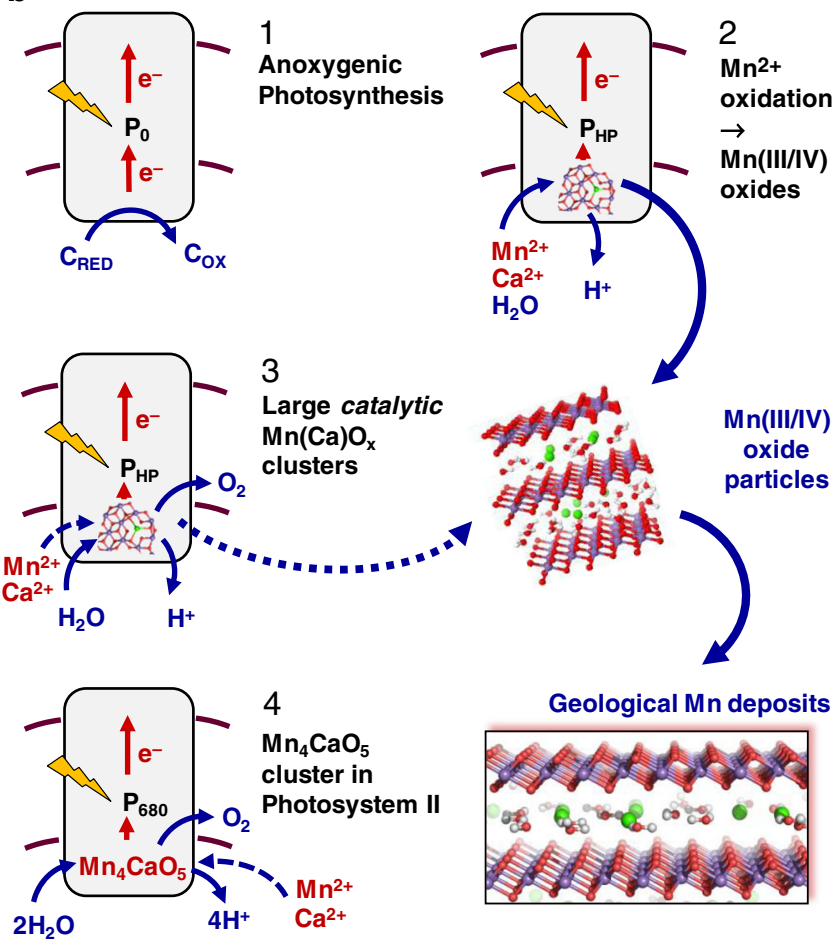

Geological Mn deposits

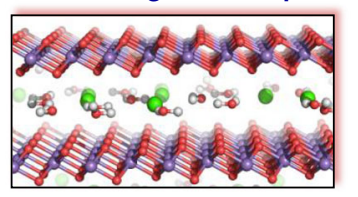

Fig. 6 Evolution of oxygenic photosynthesis and relation to geological Mn-oxide deposits. a Structural model of a birnessite fragment with $64 \mathrm{Mn}$ ions (based on published atomic coordinates, protons were added for illustration only). Atom color coding: violet, $\mathrm{Mn}(\mathrm{III} / \mathrm{IV})$ ions; red, $\mathrm{O}$ or $\mathrm{OH}$; green, $\mathrm{Ca}^{2+}$; gray, H. b Proposed sequence of evolutionary events.

(1) Starting from an early anoxygenic photosystem in a cyanobacterial ancestor, either with a low-potential or a high-potential primary donor, (2) a variant with suitable donor potential $\left(P_{H P}\right)$ and metal-binding site facilitated $\mathrm{Mn}^{2+}$ oxidation to generate protein-bound $\mathrm{Mn}(\mathrm{III}, \mathrm{IV})$-oxide clusters, which upon sedimentation contributed to geological Mn-oxide deposits. (3) The PSII-bound clusters developed into primordial wateroxidizing and $\mathrm{O}_{2}$-evolving catalytic complexes, which, (4) due to a dedicated binding site, were down-sized to the present $\mathrm{Mn}_{4} \mathrm{CaO}_{5}$ catalyst. At some point, $\mathrm{Mn}$-oxide particles also may have been involved in a quasirespiratory cycle.

extrinsic proteins and therefore could accommodate a Mn-oxide nanoparticle. Furthermore, an ancient autotroph, capable of exploiting $\mathrm{Mn}^{2+}$ as a metabolic reductant ${ }^{32,33}$, would be expected to be configured so that the donor side of the early PSII ancestor would be exposed to the environment as opposed to being sequestered within the lumen of modern thylakoids. In this context, the cyanobacterium Gloeobacter violaceous provides an interesting example. Gloeobacter occupies a basal phylogenetic position and evolved before the appearance of thylakoids. It possesses photosynthetic reaction centers that are located in the cytoplasmic membrane with the oxidizing domain of PSII facing the periplasmic space and thus the exterior of the cell ${ }^{53}$. Thus Gloeobacter provides an example of how a primordial reaction center might have been arranged to facilitate the photochemical utilization of $\mathrm{Mn}^{2+}$ as a reductant source, as originally proposed by Zubay ${ }^{32}$.

Relation to water-oxidizing synthetic Mn oxides. Birnessite and buserite are layered, typically non-crystalline metal-oxides with sheets of edge-sharing $\mathrm{MnO}_{6}$ octahedra (which corresponds to di$\mu$-oxo bridging between neighboring $\mathrm{Mn}$ ions) separated by water and cations, e.g., $\mathrm{Na}^{+}$or $\mathrm{Ca}^{2+}$, in the interlayer space ${ }^{44,45,54}$. Birnessite and buserite differ regarding the number of watercation layers in between two oxide layers (one in birnessite, two in buserite), but share the same fundamental structure of the $\mathrm{Mn}$ (III, IV) oxide layers and thus are often jointly denoted as birnessitetype Mn oxides. Notably, a Mn oxide denoted as ranciéite is isostructural to birnessite and contains $\mathrm{Mn}$ and $\mathrm{Ca}$ ions at approximately the same 4:1 stoichiometry as present in the $\mathrm{Mn}_{4} \mathrm{CaO}_{5}$ cluster of PSII ${ }^{55}$, suggesting a possible relation ${ }^{27,56-58}$. Birnessite-type $\mathrm{Mn}$ oxides are a major component of Mn-oxide ocean nodules ${ }^{44}$ and biogenic $\mathrm{Mn}$ oxides ${ }^{59}$. Their diagenetic reductive conversion to Mn-bearing carbonates, on geological time scales, may explain the early $\mathrm{Mn}$ deposits reported by Johnson et al. ${ }^{33}$. Notably, by electrodeposition and other synthesis protocols, Mn(III/IV) oxides of the birnessite type can be formed that are either active or largely inactive in water oxidation, depending on their atomic structure ${ }^{21,22,25,47,60,61}$. These $\mathrm{Mn}$ (III/ IV) oxides share key features with the $\mathrm{Mn}_{4} \mathrm{CaO}_{5}$ cluster of the biological catalyst, including joint structural motifs and facile oxidation state changes during catalytic operation ${ }^{24}$. The presence of $\mathrm{Ca}$ ions is especially favorable for water oxidation activity by synthetic manganese oxides, pointing towards similar wateroxidation mechanisms in the synthetic oxides and the biological $\mathrm{Mn}_{4} \mathrm{CaO}_{5}$ cluster of PSII ${ }^{21,22,25,62}$. Regarding their high degree of structural order, the Mn-oxide particles formed by PSII resemble electrodeposited $\mathrm{Mn}$ oxides that are able to undergo $\mathrm{Mn}(\mathrm{III})-$ $\mathrm{Mn}(\mathrm{IV})$ redox transitions, but exhibit low electrochemical water oxidation activity ${ }^{24}$. The structural characteristics that have been identified for transforming a largely inactive $\mathrm{Mn}$ oxide into an oxide with sizeable water-oxidation activity ${ }^{24}$ are apparently lacking in the Mn- oxide particles formed by PSII, which may explain the absence of detectable water-oxidation activity by the herein investigated PSII-bound Mn-oxide particle.

Mechanism of Mn-oxide formation. The basic biochemical mechanism of the here described light-induced Mn-oxide formation likely involves the initial binding of $\mathrm{Mn}^{2+}$ ions followed by $\mathrm{Mn}$ oxidation and stabilization of the oxidized $\mathrm{Mn}(\mathrm{III} / \mathrm{IV})$ ions by di- $\mu$-oxo bridging, in analogy to both the photoassembly process of today's $\mathrm{Mn}_{4} \mathrm{CaO}_{5}$ cluster ${ }^{19,20}$ and the oxidative selfassembly process in the electrodeposition of non-biological birnessite-type $\mathrm{Mn}$ oxides ${ }^{25,47}$. The formation of extended oxide particles likely involves a nucleation-and-growth mechanism. In the photosystem, the initial site of $\mathrm{Mn}^{2+}$ binding and formation of an oxide nucleus likely is provided by carboxylate and possibly imidazole sidechains of protein residues followed by an oxide growth that does not require further ligating residues. 
Oxide-incorporation hypothesis on the evolution of today's $\mathrm{Mn}_{4} \mathrm{CaO}_{5}$ cluster. Various hypotheses on the origin of the $\mathrm{Mn}_{4} \mathrm{CaO}_{5}$ cluster have been proposed. According to Raymond and Blankenship the interaction of an anoxygenic PSII with a manganese catalase, utilizing hydrogen peroxide as the source of electrons, led to the formation of today's $\mathrm{Mn}_{4} \mathrm{CaO}_{5}$ cluster ${ }^{28}$, without invoking Mn oxides. Dismukes and coworkers developed hypotheses on the evolution of oxygenic photosynthesis by focusing on the inorganic chemistry of $\mathrm{Mn}$ and bicarbonate ${ }^{63}$; their analyses could complement the herein developed ideas on the evolutionary role of Mn oxides in the future. In 2001, Russell and Hall developed their influential Mn-oxide incorporation hypothesis ${ }^{56}$. They suggested that a 'ready-made' cluster must have been co-opted whole by a (mutant?) protein ${ }^{57,58}$. Russell and Hall specifically proposed that dissolved $\mathrm{Mn}^{2+}$ ions were photooxidized at extremely short wavelengths ${ }^{64}$ to colloidal clusters of $\left[\mathrm{CaMn}_{4} \mathrm{O}_{9} \cdot 3 \mathrm{H}_{2} \mathrm{O}\right]$, which are closely related to the birnessite-type $\mathrm{Mn}$ oxide denoted as ranciciéite. Incorporation of this or a similar ready-made $\mathrm{Mn}_{4} \mathrm{Ca}$ species into a PSII ancestor would have led to the $\mathrm{Mn}_{4} \mathrm{CaO}_{5}$ cluster of today's PSII. This hypothesis is in line with analyses of Yachandra and Sauer who systematically compared the structural relations between various $\mathrm{Mn}$ oxides and the biological metal complex, revealing intriguing similarities ${ }^{27}$ (for further discussion, see SI Appendix- Supplementary Note).

Alternative hypothesis on the evolution of the $\mathrm{Mn}_{4} \mathrm{CaO}_{5}$ cluster. We see a close relation between inorganic $\mathrm{Mn}$ oxides and today's $\mathrm{Mn}_{4} \mathrm{CaO}_{5}$ cluster of PSII that differs distinctively from the Mn-oxide incorporation hypotheses outlined above. In our study, the facile formation of birnessite-type Mn- oxide particles by PSII is reported. They (i) share structural motifs with the biological cluster in PSII ${ }^{10,65}$ and biogenic Mn oxides in general ${ }^{59,66}$ and (ii) resemble synthetic $\mathrm{Mn}$ oxides closely that have been investigated as synthetic catalyst materials ${ }^{24}$. On these grounds we propose a scenario illustrated in Fig. 6: Rather than Mn-oxide incorporation, Mn-oxide nanoparticles were formed by an evolutionary precursor of PSII, inter alia enabling the formation of early geological Mn-oxide deposits. Initially, dissolved $\mathrm{Mn}^{2+}$ ions served as a source of reducing equivalents eventually needed for $\mathrm{CO}_{2}$ reduction, as has been suggested first by Zubay ${ }^{32}$ and later by others 31,33 . At a later stage, down-sized oxide particles developed into today's water-oxidizing $\mathrm{Mn}_{4} \mathrm{CaO}_{5}$ cluster. Whether the early photosynthetic reaction centers initially exhibited a sufficiently high potential for the oxidation of aqueous $\mathrm{Mn}^{2+}$ ions 67,68 or such a potential was acquired during evolution starting from a low-potential ancestor ${ }^{31}$ has to remain an open question at the present stage (Fig. 6). Olson has already favored the high-potential first hypothesis 50 years ago ${ }^{68}$, and recently such ideas have gained support based on structural and genomic comparisons from Cardona and coworkers ${ }^{69}$. We note that our hypothesis that Mn-oxide incorporation precedes the formation of the present water oxidation catalyst in PSII is independent on the earlier way of evolution of a high-potential reaction center, because such a species is needed for both processes.

Are there evolutionary relicts that may support our above hypothesis? Extensive studies on the diversity of the PSII reaction center protein D1 have revealed several atypical variants that can be distinguished phylogenetically 70,71 . These early evolved forms lack many residues needed for the binding of today's $\mathrm{Mn}_{4} \mathrm{CaO}_{5}$ cluster and could relate to ancient Mn-oxide-forming photosystems, even though today they might play other physiological roles (e.g., in the synthesis of chlorophyll $f^{72}$ ).

Summary of potential evolutionary implications. The ability for light-driven Mn-oxide formation by an ancient photosystem represents an important touchstone for evaluation of three interrelated hypotheses that each addresses a remarkable facet of the evolution of the Earth's biosphere and geosphere:

(i) The ability for the direct and facile photosynthetic formation of stable $\mathrm{Mn}(\mathrm{III} / \mathrm{IV})$-oxide particles supports that early $\mathrm{Mn}$ deposits ${ }^{33}$ resulted directly from photosynthetic activity.

(ii) Structural and functional similarities between wateroxidizing synthetic $\mathrm{Mn}$ oxides and the here described Mn-oxide formation by PSII suggests that in the evolution of PSII, there may have been a transition from extended $\mathrm{Mn}$-oxide nanoparticles towards the $\mathrm{Mn}_{4} \mathrm{CaO}_{5}$ cluster of today's PSII, as illustrated by Fig. 6 .

(iii) An early quasi-respiratory cycle has been proposed that involves the formation of $\mathrm{Mn}$ (III/IV) oxide particles followed by utilization of the oxidizing equivalents stored in the $\mathrm{Mn}$ oxide for an efficient quasi-respiratory activity in the Archean or early Paleoproterozoic, when the Earth's atmosphere had been essentially $\mathrm{O}_{2}$-free, as detailed in ref. ${ }^{65}$.

By showing that today's PSII can form birnessite-type Mnoxide particles efficiently, even without any specific protein subunits that would support Mn-oxide formation, the general biochemical feasibility is verified. This finding renders it highly likely that similarly also an ancient photosystem, the PSII ancestor, had the ability for the light-driven formation of $\mathrm{Mn}$ oxides from hexaquo $\mathrm{Mn}^{2+}$ ions. In conclusion, we believe that our successful demonstration of the photosynthetic formation of $\mathrm{Mn}(\mathrm{III} / \mathrm{IV})$-oxide particles provides relevant support for the above three hypotheses.

\section{Methods}

Preparation of PSII membrane particles. Native PSII-enriched thylakoid membrane particles were prepared from fresh market spinach following our established procedures ${ }^{35}$. Their typical $\mathrm{O}_{2}$-evolution activity (as determined by polarography with a Clark-type electrode at $27^{\circ} \mathrm{C}$ ) was $\sim 1200 \mu \mathrm{mol} \mathrm{O}_{2} \mathrm{mg}^{-1}$ chlorophyll h${ }^{-1}$, which proved the full integrity of the PSII proteins and the water-oxidizing $\mathrm{Mn}_{4} \mathrm{CaO}_{5}$ complex. We have shown earlier that this type of PSII preparation contains $\sim 200$ chlorophyll molecules per PSII reaction center ${ }^{73,74}$. When kept for prolonged time periods in the dark, the $\mathrm{Mn}_{4} \mathrm{CaO}_{5}$ complex is synchronized in the $\mathrm{S}_{1}$ state of its catalytic cycle, which is established to represent a $\mathrm{Mn}(\mathrm{III})_{2} \mathrm{Mn}(\mathrm{IV})_{2}$ oxidation state ${ }^{75,76}$.

Mn-depletion of PSII. Removal of $\mathrm{Mn}_{4} \mathrm{CaO}_{5}$ and of the three extrinsic proteins of PSII (PsbQ, PsbP, and PsbO) was carried out using a literature procedure and evaluated using metal quantification and gel electrophoresis (see below) ${ }^{36}$. PSII membranes were dissolved at $200 \mu \mathrm{g}$ chlorophyll $\mathrm{mL}^{-1}$ in a high-salt buffer $(30 \mathrm{~mL})$ containing $20 \mathrm{mM}$ TEMED (N,N,N',N'-tetramethylethylenediamine) as a reductant for the PSII-bound Mn(III,IV) ions, $20 \mathrm{mM}$ MES (2-(N-morpholino)ethane-sulfo-

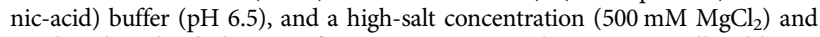
incubated in the dark on ice for $10 \mathrm{~min}$. PSII membranes were pelleted by centrifugation (Sorvall RC26, $12 \mathrm{~min}, 50,000 \times g, 4^{\circ} \mathrm{C}$ ), the pellet was three times washed by dissolution in a buffer $(30 \mathrm{~mL}$ ) containing $35 \mathrm{mM} \mathrm{NaCl}$ and $20 \mathrm{mM}$ TRIS (tris (hydroxymethyl)aminomethane) buffer ( $\mathrm{pH} 9.0)$ and pelleting by centrifugation as above, and the final pellet of Mn-depleted PSII membranes was dissolved at $\sim 1 \mathrm{mg}$ chlorophyll $\mathrm{mL}^{-1}$ in a buffer containing $1 \mathrm{M}$ glycine-betaine, $15 \mathrm{mM} \mathrm{NaCl}, 5 \mathrm{mM}$ $\mathrm{CaCl}_{2}, 5 \mathrm{mM} \mathrm{MgCl}_{2}$, and $25 \mathrm{mM}$ MES buffer (pH 6.3). The PSII preparations ( $2 \mathrm{mg}$ chlorophyll $\mathrm{mL}^{-1}$ ) were thoroughly homogenized by gentle brushing and frozen in liquid nitrogen for the spectroscopic experiments. The Mn-depleted PSII showed zero $\mathrm{O}_{2}$-evolution activity as revealed by polarography.

TXRF analysis. X-ray emission spectra were recorded on a Picofox instrument (Bruker) and metal contents of PSII samples were determined from the data using the (fit) routines available with the spectrometer ${ }^{39}$. PSII membranes were adjusted to a chlorophyll concentration of $1-2 \mathrm{mM}$ and to a $20 \mu \mathrm{L}$ aliquot, a gallium concentration standard ( $1 \mathrm{mg} \mathrm{mL}^{-1}, 20 \mu \mathrm{L}$; Sigma-Aldrich) was added, and samples were homogenized by brief sonication (see Supplementary Fig. 1). A $5 \mu \mathrm{L}$ aliquot of the samples was pipetted on clean quartz discs for TXRF, dried on a heating plate, loaded into the spectrometer, and TXRF spectra were recorded within 10-30 min. At least three repetitions of each sample and three independently prepared samples of each PSII preparation were analyzed. The TXRF data on Mn-oxide formation by Mn-depleted 
PSII shown in Table 1 were obtained using the same illumination and centrifugation protocol also used for preparation of the X-ray spectroscopy samples of Fig. 5.

Optical absorption spectroscopy and illumination procedures. For the optical absorption spectroscopy experiments, stock suspensions of the PSII preparations were diluted at $20 \mu \mathrm{g}$ chlorophyll $\mathrm{mL}^{-1}(\sim 0.1 \mu \mathrm{M}$ PSII centers) in a buffer $(3 \mathrm{~mL})$ containing $1 \mathrm{M}$ glycine-betaine, $15 \mathrm{mM} \mathrm{NaCl}, 5 \mathrm{mM} \mathrm{CaCl}_{2}, 5 \mathrm{mM} \mathrm{MgCl}_{2}$, and 25 mM MES buffer (pH 6.3-8.5) and reactants (oxidized 2,6-dichlorophenol-indophenol $=$ DCPIP ${ }^{\text {ox }}$ from Fluka, other electron acceptors as in Supplementary Fig. $11, \mathrm{MnCl}_{2}$ ) were added at indicated concentrations. The $\mathrm{pH}$ was routinely controlled prior to and after the illumination assays in the actual cuvette and found to be stable within $\pm 0.2 \mathrm{pH}$ units within a time period of at least $20 \mathrm{~min}$. Optical absorption spectra of the samples in a 300-900 nm range were recorded within about $10 \mathrm{~s}$ at given time intervals (about $0.3-1.0 \mathrm{~min}$ ) in a $3 \mathrm{~mL}$ quartz cuvette (Helma QS1000, $1 \mathrm{~cm}$ pathlength) using a Cary 60 spectrometer (Agilent). Alternatively, time traces of absorption were recorded at selected wavelengths (i.e., 604 $\mathrm{nm}$ to monitor DCPIPox reduction) for up to $30 \mathrm{~min}$. Temperature logging revealed that the sample temperature varied by $<2{ }^{\circ} \mathrm{C}$ within the extended illumination periods. PSII-sample filled cuvettes in the spectrometer were continuously illuminated from the top side using a white-light lamp (Schott KL1500, halogen light bulb with cold-light reflector) with attenuation option, which was directed through a heat-protection filter (Schott KG5) to the cuvette by a $\sim 20 \mathrm{~cm}$ light-guide (the full cuvette volume was homogenously illuminated). The combination of light source, KG5 filter, light guide, and cuvette material resulted in an effective spectral range of about $400-750 \mathrm{~nm}$ (limits correspond to the $10 \%$ level) effectively excluding UV irradiation, thereby minimizing potential interferences due to peroxide formation resulting from direct $\mathrm{Mn}$-oxide excitation, and sample heating due to infrared light (thermal radiation). Several spectra (or time points) were recorded in the dark (prior to and after addition of, e.g., DCPIP), the light was switched on (or off) at indicated time points, and data were recorded on a PC linked to the spectrometer. Evaluation and fit analysis of absorption data was carried out using the Origin software (OriginLab). Light intensities at the sample center position were determined using a calibrated sensor device inserted in the spectrometer.

X-ray absorption spectroscopy. XAS at the Mn K-edge was performed at beamline KMC-3 at the BESSY-II synchrotron (Helmholtz Zentrum Berlin) with the storage ring operated in top-up mode ( 250 or $300 \mathrm{~mA}$ ), using a standard set-up as described in refs. ${ }^{25,77}$. A double-crystal $\mathrm{Si}[111]$ monochromator was used for energy scanning, the sample X-ray fluorescence was monitored with an energyresolving 13-element germanium detector (Canberra) or a 13-element silicon-drift detector (RaySpec), and samples were held in a liquid-helium cryostat (Oxford) at $20 \mathrm{~K}$ (in a $0.2 \mathrm{bar} H e$ heat-exchange gas atmosphere at an angle of $55^{\circ}$ to the incident X-ray beam). The X-ray spot size on the sample was shaped by slits to about 1 (vertical) $\times 5$ (horizontal) $\mathrm{mm}^{2}$, the X-ray flux was $\sim 10^{10}$ photons $\mathrm{s}^{-1}$, the EXAFS scan duration was $\sim 10-20 \mathrm{~min}$. The energy axis was calibrated $( \pm 0.1 \mathrm{eV}$ accuracy) using a Gaussian fit to the pre-edge peak $(6543.3 \mathrm{eV})$ in the transmission spectrum of a permanganate $\left(\mathrm{KMnO}_{4}\right)$ powder sample, which was measured in parallel to the PSII samples. For XAS data evaluation, up to 30 deadtime-corrected, energy-calibrated $\left(I / I_{0}\right)$ XAS monochromator scans (each on a fresh sample spot) were averaged and normalized XANES and EXAFS spectra were extracted after background subtraction using in-house software ${ }^{78}$. EXAFS simulations in $k$-space were carried out using in-house software (SimX) and scattering phase functions calculated with FEFF9. $0^{79}\left(S_{0}{ }^{2}=0.8\right)$. Calculation of the filtered $R$-factor $\left(R_{\mathrm{F}}\right.$, the difference in \% between fit curve and Fourier-backtransform of the experimental data in a 1-5 ^ region of reduced distance $)^{80}$ facilitated evaluation of the EXAFS fit quality. Fourier-transforms of EXAFS spectra were calculated with cos windows extending over $10 \%$ of both $k$-range ends.

Sample preparation for XAS. Powder samples of manganese reference compounds (Mn oxides) were prepared from commercially available chemicals $\left(\mathrm{MnCl}_{2}\right.$, Mn oxides) or from material (birnessite) that was kindly provided by the group of P. Kurz (Uni. Freiburg, Germany), diluted by grinding with boron-nitride (BN) to a level, which resulted in $<15 \%$ absorption at the K-edge maximum to avoid flattening effects in fluorescence-detected XAS spectra, loaded into Kapton-covered acrylicglass holders, and frozen in liquid nitrogen. Aqueous $\mathrm{MnCl}_{2}(20 \mathrm{mM})$ samples were prepared at $\mathrm{pH}$ 7.0. Unless otherwise specified, PSII samples were prepared as follows: Mn-depleted PSII samples $(3 \mathrm{~mL}$ ) were prepared similar to the samples for optical absorption spectroscopy (see above), the $\mathrm{pH}$ was adjusted to the desired value ( $\mathrm{pH} 7$ or 8.5), and samples were illuminated for $3 \mathrm{~min}$ at $1000 \mu \mathrm{E} \mathrm{m}^{-2} \mathrm{~s}^{-1}$ or kept in the dark as a control after addition of $240 \mu \mathrm{M} \mathrm{MnCl}_{2}$ and $60 \mu \mathrm{M}$ PPBQ ${ }^{\text {ox }}$. Thereafter, the cuvette volume was rapidly mixed with ice-cold MES buffer $(7 \mathrm{~mL}$, $\mathrm{pH} 7$ or 8.5 , see above for ingredients) on ice in the dark, the $\mathrm{pH}$ was measured using a $\mathrm{pH}$ electrode and, if necessary, readjusted to the desired value $(+/-0.1 \mathrm{pH}$ units), the PSII membranes were pelleted by centrifugation $(10 \mathrm{~min}, 20,000 \times g$, $2{ }^{\circ} \mathrm{C}$ ), and kept on ice. Several of these sample types were rapidly merged on ice in the dark by loading $(\sim 30 \mu \mathrm{L})$ into XAS holders, which were immediately frozen in liquid nitrogen. Native PSII samples were prepared by pelleting of dark-adapted $\mathrm{O}_{2^{-}}$ evolving PSII membrane particles ( $\sim 8 \mathrm{mg}$ chlorophyll $\mathrm{mL}^{-1}, \mathrm{pH} 6.3$ ), loading of the pellet material into XAS holders, and freezing in liquid nitrogen ${ }^{76}$. The shown XAS data for the electrodeposited $\mathrm{Mn}$ oxides has been collected in the context of earlier studies ${ }^{21,22,47}$ and replotted.

Solubilization of PSII membrane particles to yield membrane-free PSII complexes. Mn-depleted PSII membrane particles were solubilized as described by Haniewicz et al. ${ }^{81}$. In brief, $20 \mathrm{mM} \beta$-dodecylmaltoside ( $\beta$-DM) was added to the membranes with a chlorophyll concentration of $2 \mathrm{mg} \mathrm{mL}^{-1}$. After incubation for $30 \mathrm{~min}$ at $4{ }^{\circ} \mathrm{C}$ in the dark, the solubilized material was separated from the insoluble fraction by centrifugation at $40,000 \times g$ for $20 \mathrm{~min}$ at $4^{\circ} \mathrm{C}$. From the supernatant containing the solubilized Mn-depleted PSII, XAS samples were prepared as follows. An aliquot of the solution with solubilized PSII was added to MES buffer $(\mathrm{pH}$ 7.0) containing $240 \mu \mathrm{M} \mathrm{MnCl}_{2}, 5 \mathrm{mM} \mathrm{CaCl}_{2}, 60 \mu \mathrm{M} \mathrm{PPBQ}$, and $0.03 \%$ (v/v) $\beta$-DM to a final chlorophyll concentration of $20 \mu \mathrm{g} \mathrm{mL}^{-1}$ and the sample was illuminated for $1 \mathrm{~min}$ at $1000 \mu \mathrm{E} \mathrm{m}^{-2} \mathrm{~s}^{-1}$. To remove unbound $\mathrm{Mn}$ and electron acceptor, the sample was precipitated by adding polyethylene-glycol (PEG 6000) to a final concentration of $4.4 \%(\mathrm{w} / \mathrm{v})$ and a subsequent centrifugation step $(16,000 \times g$, $\left.10 \mathrm{~min}, 4^{\circ} \mathrm{C}\right)^{82}$. The pellet was resuspended in MES buffer $(\mathrm{pH} 7.0)$ and the PEG precipitation and centrifugation procedure was repeated twice. After the final washing step, the pellet was resuspended in a small volume of buffer and transferred to the sample holder as described above.

Reporting summary. Further information on research design is available in the Nature Research Reporting Summary linked to this article.

\section{Data availability}

All data needed to support the conclusions of this manuscript are included in the main text and SI Appendix. The source data underlying Figs. 3-5 are provided as a Source Data file. Source data are provided with this paper.

Received: 6 March 2020; Accepted: 2 November 2020;

Published online: 30 November 2020

\section{References}

1. Rosing, M. T. \& Frei, R. U-rich Archaean sea-floor sediments from Greenland - indications of $>3700 \mathrm{Ma}$ oxygenic photosynthesis. Earth Planet. Sci. Lett. 217, 237-244 (2004).

2. Fischer, W. W., Hemp, J. \& Johnson, J. E. Manganese and the evolution of photosynthesis. Orig. Life Evol. Biosph. 45, 351-357 (2015).

3. Anbar, A. D., Till, C. B. \& Hannah, M. A. Bridge the planetary divide. Nature 539, 25-27 (2016)

4. McEvoy, J. P. \& Brudvig, G. W. Water-splitting chemistry of photosystem II. Chem. Rev. 106, 4455-4483 (2006).

5. Dau, H. \& Haumann, M. The manganese complex of photosystem II in its reaction cycle-basic framework and possible realization at the atomic level. Coord. Chem. Rev. 252, 273-295 (2008).

6. Cox, N. \& Messinger, J. Reflections on substrate water and dioxygen formation. Biochim. Biophys. Acta 1827, 1020-1030 (2013).

7. Perez-Navarro, M., Neese, F., Lubitz, W., Pantazis, D. A. \& Cox, N. Recent developments in biological water oxidation. Curr. Opin. Chem. Biol. 31, 113-119 (2016).

8. Barber, J. Photosynthetic water splitting by the $\mathrm{Mn}_{4} \mathrm{Ca}_{2}+\mathrm{OX}$ catalyst of photosystem II: its structure, robustness and mechanism. Q. Rev. Biophys. 50, e13 (2017).

9. Nowicka, B. \& Kruk, J. Powered by light: phototrophy and photosynthesis in prokaryotes and its evolution. Microbiol. Res. 186, 99-118 (2016).

10. Shen, J. R. The structure of photosystem II and the mechanism of water oxidation in photosynthesis. Annu. Rev. Plant Biol. 66, 23-48 (2015).

11. Su, X. D. et al. Structure and assembly mechanism of plant $C_{2} S_{2} M_{2}$-type PSII-LHCII supercomplex. Science 357, 815-820 (2017).

12. Dau, H., Zaharieva, I. \& Haumann, M. Recent developments in research on water oxidation by photosystem II. Curr. Opin. Chem. Biol. 16, 3-10 (2012).

13. Nelson, N. \& Junge, W. Structure and energy transfer in photosystems of oxygenic photosynthesis. Annu. Rev. Biochem. 84, 659-683 (2015).

14. Vinyard, D. J. \& Brudvig, G. W. Progress toward a molecular mechanism of water oxidation in photosystem II. Annu. Rev. Phys. Chem. 68, 101-116 (2017).

15. Dau, H. \& Haumann, M. Eight steps preceding O-O bond formation in oxygenic photosynthesis-a basic reaction cycle of the photosystem II manganese complex. Biochim. Biophys. Acta 1767, 472-483 (2007).

16. Barber, J. Photosynthetic energy conversion: natural and artificial. Chem. Soc Rev. 38, 185-196 (2009).

17. Dau, H. et al. The mechanism of water oxidation: from electrolysis via homogeneous to biological catalysis. ChemCatChem 2, 724-761 (2010). 
18. Li, J. et al. Frontiers of water oxidation: the quest for true catalysts. Chem. Soc. Rev. 46, 6124-6147 (2017).

19. Bao, H. \& Burnap, R. L. Photoactivation: the light-driven assembly of the water oxidation complex of photosystem II. Front. Plant Sci. 7, 578 (2016).

20. Dasgupta, J., Ananyev, G. M. \& Dismukes, G. C. Photoassembly of the wateroxidizing complex in photosystem II. Coord. Chem. Rev. 252, 347-360 (2008).

21. Zaharieva, I. et al. Synthetic manganese-calcium oxides mimic the wateroxidizing complex of photosynthesis functionally and structurally. Energy Environ. Sci. 4, 2400-2408 (2011).

22. Wiechen, M., Zaharieva, I., Dau, H. \& Kurz, P. Layered manganese oxides for water-oxidation: alkaline earth cations influence catalytic activity in a photosystem II-like fashion. Chem. Sci. 3, 2330-2339 (2012).

23. Kurz, P. Biomimetic water-oxidation catalysts: Manganese oxides. Top. Curr. Chem. 371, 49-72 (2016).

24. Zaharieva, I. et al. Water oxidation catalysis - role of redox and structural dynamics in biological photosynthesis and inorganic manganese oxides. Energy Environ. Sci. 9, 2433-2443 (2016).

25. González-Flores, D. et al. Electrosynthesis of biomimetic manganese-calcium oxides for water oxidation catalysis - atomic structure and functionality. ChemSusChem 9, 379-387 (2016).

26. Blankenship, R. E. \& Hartman, H. The origin and evolution of oxygenic photosynthesis. Trends Biochem. Sci. 23, 94-97 (1998).

27. Sauer, K. \& Yachandra, V. K. A possible evolutionary origin for the Mn4 cluster of the photosynthetic water oxidation complex from natural $\mathrm{MnO}_{2}$ precipitates in the early ocean. Proc. Natl Acad. Sci. USA 99, 8631-8636 (2002).

28. Raymond, J. \& Blankenship, R. The origin of the oxygen-evolving complex. Coord. Chem. Rev. 252, 377-383 (2008).

29. Khorobrykh, A. et al. Evolutionary origins of the photosynthetic water oxidation cluster: bicarbonate permits $\mathrm{Mn}(2+)$ photo-oxidation by anoxygenic bacterial reaction centers. Chembiochem 14, 1725-1731 (2013).

30. Cardona, T. Reconstructing the origin of oxygenic photosynthesis: do assembly and photoactivation recapitulate evolution? Front. Plant Sci. 7, 257 (2016).

31. Martin, W. F., Bryant, D. A. \& Beatty, J. T. A physiological perspective on the origin and evolution of photosynthesis. FEMS Microbiol. Rev. 42, 205-231 (2018).

32. Zubay, G. Origins of Life on Earth and in the Cosmos. (Academic Press, 1996).

33. Johnson, J. E. et al. Manganese-oxidizing photosynthesis before the rise of cyanobacteria. Proc. Natl Acad. Sci. USA 110, 11238-11243 (2013).

34. Zhang, M. et al. Structural insights into the light-driven auto-assembly process of the water oxidizing Mn4CaO5-cluster in photosystem II. Elife 6, e26933 (2017).

35. Schiller, H. \& Dau, H. Preparation protocols for high-activity photosystem II membrane particles of green algae and higher plants, $\mathrm{pH}$ dependence of oxygen evolution and comparison of the S2-state multiline signal by X-band EPR spectroscopy. J. Photochem. Photobiol. 55, 138-144 (2000).

36. Allakhverdiev, S. I. et al. Reconstitution of the water-oxidizing complex in manganese-depleted photosystem II complexes by using synthetic binuclear manganese complexes. Biochemistry 33, 12210-12214 (1994).

37. Bricker, T. M., Roose, J. L., Fagerlund, R. D., Frankel, L. K. \& Eaton-Rye, J. J. The extrinsic proteins of photosystem II. Biochim. Biophys. Acta 1817, 121-142 (2012).

38. Roose, J. L., Frankel, L. K., Mummadisetti, M. P. \& Bricker, T. M. The extrinsic proteins of photosystem II: update. Planta 243, 889-908 (2016).

39. Klockenkämper, R. Total Reflection X-Ray Fluorescence Analysis. (Wiley, 1996).

40. Vernon, L. P. \& Shaw, E. R. Photoreduction of 2,6-dichlorophenolindophenol by diphenylcarbazide: a photosystem 2 reaction catalyzed by tris-washed chloroplasts and subchloroplast fragments. Plant Physiol. 44, 1645-1649 (1969).

41. Eross, K., Svehla, G. \& Erdey, L. Use of 2,6-Dichlorophenolindophenol as indicator in acid-base titrations. Anal. Chim. Acta 31, 246-250 (1964).

42. Velitchkova, M. Y. \& Picorel, R. Photobleaching of photosynthetic pigments in spinach thylakoid membranes. Effect of temperature, oxygen and DCMU. Biophys. Chem. 107, 25-32 (2004).

43. Müller, C., Liebisch, P., Barra, M., Dau, H. \& Haumann, M. The location of calcium in the manganese complex of oxygenic photosynthesis studied by $\mathrm{X}-$ ray absorption spectroscopy at the Ca K-edge. Phys. Scr. T115, 847-850 (2005).

44. Post, J. E. Manganese oxide minerals: crystal structures and economic and environmental significance. Proc. Natl Acad. Sci. USA 96, 3447-3454 (1999).

45. Suib, S. L. Porous manganese oxide octahedral molecular sieves and octahedral layered materials. Acc. Chem. Res. 41, 479-487 (2008).

46. Lee, S. Y. et al. Screen-printed calcium-birnessite electrodes for water oxidation at neutral $\mathrm{pH}$ and an "Electrochemical Harriman series". ChemSusChem 7, 3442-3451 (2014).
47. Zaharieva, I. et al. Electrosynthesis, functional and structural characterization of a water-oxidizing manganese oxide. Energy Environ. Sci. 5, 7081-7089 (2012).

48. Mattioli, G., Zaharieva, I., Dau, H. \& Guidoni, L. Atomistic texture of amorphous manganese oxides for electrochemical water splitting revealed by ab initio calculations combined with X-ray spectroscopy. J. Am. Chem. Soc. 137, 10254-10267 (2015)

49. Chen, C., Kazimir, J. \& Cheniae, G. M. Calcium modulates the photoassembly of photosystem II (Mn)4-clusters by preventing ligation of nonfunctional high-valency states of manganese. Biochemistry 34, 13511-13526 (1995).

50. Vinyard, D. J. et al. Photosystem II oxygen-evolving complex photoassembly displays an inverse $\mathrm{H} / \mathrm{D}$ solvent isotope effect under chloride-limiting conditions. Proc. Natl Acad. Sci. USA 116, 18917-18922 (2019).

51. Ifuku, K. Localization and functional characterization of the extrinsic subunits of photosystem II: an update. Biosci. Biotechnol. Biochem. 79, 1223-1231 (2015).

52. Niederman, R. A. Development and dynamics of the photosynthetic apparatus in purple phototrophic bacteria. Biochim. Biophys. Acta 1857, 232-246 (2016)

53. Rexroth, S. et al. The plasma membrane of the cyanobacterium Gloeobacter violaceus contains segregated bioenergetic domains. Plant Cell 23, 2379-2390 (2011).

54. Post, J. E. \& Veblen, D. R. Crystal structure determinations of synthetic sodium, magnesium, and potassium birnessite using TEM and the Rietveld method. Am. Mineral. 75, 477-489 (1990).

55. Ertl, A. et al. Rancieite crystals from Friesach, Carinthia, Austria. Eur. J. Miner 17, 163-172 (2005).

56. Russell, M. J. \& Hall, A. J. The onset of life and the dawn of oxygenic photosynthesis: respective roles of cubane core structures $\left[\mathrm{Fe}_{4} \mathrm{~S}_{4}\right]^{2+}$ and transient $\left[\mathrm{Mn}_{4} \mathrm{O}_{4}\right]^{4+}[\mathrm{OCaO}]^{2}$. in Sixth Int. Conference on Carbon Dioxide Utilization, p. 49 (Breckenridge, Colorado, 2001).

57. Russell, M. J. \& Hall, A. J. From geochemistry to biochemistry: chemiosmotic coupling and transition element clusters in the onset of life and photosynthesis. Geochem. N. 113, 6-12 (2002).

58. Russell, M. J., Hall, A. J. \& Mellersh, A. R. Natural and Laboratory-Simulated Thermal Geochemical Processes. (Springer, Dordrecht, 2003). .

59. Tebo, B. M. et al. Biogenic manganese oxides: properties and mechanisms of formation. Annu. Rev. Earth Planet. Sci. 32, 287-328 (2004).

60. Bergmann, A., Zaharieva, I., Dau, H. \& Strasser, P. Electrochemical water splitting by layered and 3D cross-linked manganese oxides: correlating structural motifs and catalytic activity. Energy Environ. Sci. 6, 2745-2755 (2013).

61. Iyer, A. et al. Water oxidation catalysis using amorphous manganese oxides, octahedral molecular sieves (OMS-2), and octahedral layered (OL-1) manganese oxide structures. J. Phys. Chem. C 116, 6474-6483 (2012).

62. Frey, C. E., Wiechen, M. \& Kurz, P. Water-oxidation catalysis by synthetic manganese oxides - systematic variations of the calcium birnessite theme. Dalton Trans. 43, 4370-4379 (2014).

63. Dismukes, G. C. et al. The origin of atmospheric oxygen on Earth the innovation of oxygenic photosynthesis. Proc. Natl Acad. Sci. USA 98, 2170-2175 (2001).

64. Anbar, A. D. \& Holland, H. D. The photochemistry of manganese and the origin of banded iron formations. Geochim. Cosmochim. Acta 56, 2595-2603 (1992).

65. Kern, J. et al. Structures of the intermediates of Kok's photosynthetic water oxidation clock. Nature 563, 421-425 (2018).

66. Dau, H., Nürnberg, D. J. \& Burnap, R. L. Bioenergetics: Oxygen Production and Reduction Ch. 18 (World Scientific Publishers, Singapore, 2019).

67. Allen, J. F. \& Nield, J. Redox tuning in photosystem II. Trends Plant Sci. 22, 97-99 (2017).

68. Olson, J. M. The evolution of photosynthesis. Science 168, 438-446 (1970).

69. Cardona, T. \& Rutherford, A. W. Evolution of photochemical reaction centres: more twists? Trends Plant Sci. 24, 1008-1021 (2019).

70. Cardona, T., Murray, J. W. \& Rutherford, A. W. Origin and evolution of water oxidation before the last common ancestor of the Cyanobacteria. Mol. Biol. Evol. 32, 1310-1328 (2015).

71. Murray, J. W. Sequence variation at the oxygen-evolving centre of photosystem II: a new class of 'rogue' cyanobacterial D1 proteins. Photosynth. Res. 110, 177-184 (2012).

72. Ho, M. Y., Shen, G., Canniffe, D. P., Zhao, C. \& Bryant, D. A. Light-dependent chlorophyll $\mathrm{f}$ synthase is a highly divergent paralog of PsbA of photosystem II. Science 353, aaf9178 (2016).

73. Barra, M., Haumann, M. \& Dau, H. Specific loss of the extrinsic $18 \mathrm{kDa}$ protein from photosystem II upon heating to $47^{\circ} \mathrm{C}$ causes inactivation of oxygen evolution likely due to $\mathrm{Ca}$ release from the Mn-complex. Photosynth. Res. 84, 231-237 (2005).

74. Barra, M. et al. Intermediates in assembly by photoactivation after thermally accelerated disassembly of the manganese complex of photosynthetic water oxidation. Biochemistry 45, 14523-14532 (2006). 
75. Zaharieva, I. et al. Room-temperature energy-sampling $\mathrm{K} \beta \mathrm{X}$-ray emission spectroscopy of the Mn4Ca complex of photosynthesis reveals three manganese-centered oxidation steps and suggests a coordination change prior to $\mathrm{O} 2$ formation. Biochemistry 55, 4197-4211 (2016).

76. Haumann, M. et al. Structural and oxidation state changes of the photosystem II manganese complex in four transitions of the water oxidation cycle (S0 $\rightarrow$ $\mathrm{S} 1, \mathrm{~S} 1 \rightarrow \mathrm{S} 2, \mathrm{~S} 2 \rightarrow \mathrm{S} 3$, and S3,4 $\rightarrow \mathrm{S} 0$ ) characterized by X-ray absorption spectroscopy at $20 \mathrm{~K}$ and room temperature. Biochemistry 44, 1894-1908 (2005).

77. Shevchenko, D. et al. Water oxidation by manganese oxides formed from tetranuclear precursor complexes: the influence of phosphate on structure and activity. Phys. Chem. Chem. Phys. 16, 11965-11975 (2014).

78. Dau, H., Liebisch, P. \& Haumann, M. X-ray absorption spectroscopy to analyze nuclear geometry and electronic structure of biological metal centers potential and questions examined with special focus on the tetra-nuclear manganese complex of oxygenic photosynthesis. Anal. Bioanal. Chem. 376, 562-583 (2003).

79. Rehr, J. J., Kas, J. J., Vila, F. D., Prange, M. P. \& Jorissen, K. Parameter-free calculations of X-ray spectra with FEFF9. Phys. Chem. Chem. Phys. 12, 5503-5513 (2010).

80. Dittmer, J. \& Dau, H. On the influence of multiple scattering contributions to the Extended X-ray Absorption Fine Structure (EXAFS) spectra of the photosystem II manganese complex. Ber. Bunsenges. Phys. Chem. 100, 1993-1998 (1996).

81. Haniewicz, P. et al. Isolation of plant photosystem II complexes by fractional solubilization. Front. Plant Sci. 6, 1100 (2015).

82. Nicholson, W. V., Shepherd, F. H., Rosenberg, M. F., Ford, R. C. \& Holzenburg, A. Structure of photosystem II in spinach thylakoid membranes: comparison of detergent-solubilized and native complexes by electron microscopy. Biochem. J. 315, 543-547 (1996).

\section{Acknowledgements}

We thank I. Zizak, G. Schuck, and colleagues (Helmholtz Zentrum Berlin) for technical support in the X-ray experiments at the BESSY synchrotron. We thank P. Kurz (Universität Freiburg) for providing samples of birnessite and buserite. We gratefully acknowledge financial support by the Deutsche Forschungsgemeinschaft (DFG, German Research Foundation) within SFB 1078 (project A4) and in form of an Emmy Noether project awarded to D. Nürnberg. The Einstein Foundation Berlin supported this research by an Einstein Fellow project awarded to R. Burnap. Moreover, this study has been funded by the Deutsche Forschungsgemeinschaft under Germany's Excellence Strategy EXC 2008/1 - 390540038.

\section{Author contributions}

H.D. designed the study. P.C., S.F., J.H., N.O., R.A., B.Y., and D.J.N. performed the experiments. P.C., M.H., and I.Z. analyzed the data. R.L.B., D.J.N., M.H., and H.D. wrote the manuscript.

\section{Funding}

Open Access funding enabled and organized by Projekt DEAL.

\section{Competing interests}

The authors declare no competing interests.

\section{Additional information}

Supplementary information is available for this paper at https://doi.org/10.1038/s41467 020-19852-0.

Correspondence and requests for materials should be addressed to H.D.

Peer review information Nature Communications thanks the anonymous reviewers for their contribution to the peer review of this work. Peer review reports are available.

Reprints and permission information is available at http://www.nature.com/reprints

Publisher's note Springer Nature remains neutral with regard to jurisdictional claims in published maps and institutional affiliations.

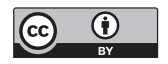

Open Access This article is licensed under a Creative Commons Attribution 4.0 International License, which permits use, sharing, adaptation, distribution and reproduction in any medium or format, as long as you give appropriate credit to the original author(s) and the source, provide a link to the Creative Commons license, and indicate if changes were made. The images or other third party material in this article are included in the article's Creative Commons license, unless indicated otherwise in a credit line to the material. If material is not included in the article's Creative Commons license and your intended use is not permitted by statutory regulation or exceeds the permitted use, you will need to obtain permission directly from the copyright holder. To view a copy of this license, visit http://creativecommons.org/ licenses/by/4.0/.

(C) The Author(s) 2020, corrected publication 2021 